\title{
Economic Valuation of Spiritual Site: Case from Tapoban, Nepal
}

\author{
Amrit Sharma1, Ganesh Paudel ${ }^{2}$, Tej Kumar Shrestha ${ }^{3}$, Sushma Tripathi ${ }^{4}$ \\ ${ }^{I}$ Department of National Parks and Wildlife Conservation, Nepal \\ ${ }^{2}$ Department of Forests and Soil Conservation, Nepal \\ ${ }^{3}$ Lumbini Environmental Services Pvt. Ltd., Nepal \\ ${ }^{4}$ Freelancer Botanist, Nepal
}

*Corresponding Author: Tej Kumar Shrestha, Lumbini Environmental Services Pvt. Ltd., Nepal

\begin{abstract}
Forest has been valued through several perspectives. Although forest has immense spiritual value it is still being ignored by forest managers in forest management. Considering the novelty and necessity of evaluating environmental economics of forest spiritual sites in developing countries like Nepal, this study was focused on evaluation of willingness to pay (WTP) for spiritual sites as a case study, using Travel Cost Method. Altogether 45 respondents that visited Tapoban, commune and spiritual site of Kathmandu valley were randomly selected and collected primary data viz, the travel cost, time, activity cost, activity time and other expenses made by visitors. Data was analyzed by using standard statistical tools. The opportunity cost of the visitor was NRs 728.14 (1 US\$ = NRs. 114.874). Around 66\% of the respondents said that trees have positive role in meditation. Likewise, $52 \%$ respondents have spiritual purpose and other $47 \%$ respondents have recreation purpose to visit this site. Economic value of spiritual site was NRs.784.37 per hour that illustrates that visitors are highly willing to pay for spiritual site. It is suggested that spiritual valuation of forest is essential not only for decision-making but also for the plan and policy making for the optimum, wise and rational utilization of forest.
\end{abstract}

Keywords: Opportunity Cost, Spiritual site, Well-being, Willing ness to pay

\section{INTRODUCTION}

The intangible value of forest is taking momentum even more than the tangible value ie, timber value of forest in present world (Himes-Cornell et al., 2018). Recreation in natural environment has extensively increased in recent decades with rapid urbanization. Equipping the natural recreational venues together with optimizing their usage is regarded as one of the important duties of forest managers. The demand of forest land for recreation and spiritual purpose is increasing these days. Various methods have been proposed so far to evaluate recreational and spiritual sites and determine the willingness to pay which depends on the regional condition and applied method. Hotelling (1947) concluded that the highest travel cost to reach the site represents the recreational value of any site. Concerns has been raised about the proper valuation of the world's forests based on the market distortions for timber products or inadequate data on Non-Timber Forest Products. An additional challenge is to uncover the economic worth of non-market services provided by forest ecosystems (De Root et al., 2002). This has led to a growing number of publications addressing the indirect valuation of forest ecosystem services which has local benefits and global relevance (Joshi and Joshi, 2018). The use values are important, and their provision are primary objective of public land management in the past. Gradually, public land managers are confronted with demands arising from passive use values such as the knowledge that specific ecosystems exist or will be available for future generations to enjoy.

All notions of value; moral, spiritual, cultural, aesthetic, economic, ecological are important for forest conservation and sustainable use. The passive value, non-anthropocentric values such as moral and spiritual values, should be considered in decision-making (MEA, 2005). Varieties of forest products including great spiritual value can be extracted from forest. Various spiritual values have been associated with forests in wealthy societies (Loomis, 1998), and in some cases poorer societies too. 
The totality of ecosystem services including spiritual value of forest will understate true willingness to pay by the amount of consumer surplus (Costanza et al, 1997). Environmental valuation is raised arguing that failure to do so will result in significant under-valuation of environmental resources in policy and management decision making (Costanza et al, 1987). A variety of motivations for passive value are proposed in the literature (Boyle and Bishop 1985). The motivations include several types of altruism as well as bequest motives. Environmental and natural value is also affected by the cultural background (Cooper, 2019).

Economic development is often associated with rising demand for environmental amenities. Increasingly, society is placing greater demands on wilderness areas for a variety of products including biodiversity, wildlife habitats, and recreation opportunities including spiritual value of forest. Resource managers are facing decision making problems due to lack of true assessment of spiritual sites that balance society's different needs and values, while trying to ensure ecosystem sustainable integrity. Valuation of ecosystem's goods is through an important and desired tool in resource management; proper valuation of forest is still lacking. This is particularly important in a world of limited financial resources and environmental valuation, in combination with strong demand pressures for the better forest management. Although the spiritual value of forest is essential for human well-being it has been ignored in forest management. The spiritual importance of forest is increasing day-by-day, but the valuation and documentation is very rare, and this gap can be narrowed by the research on spiritual valuation. Sustainable forest management should also consider the spiritual value of forest and therefore spiritual valuation of forest is must for the wise, rational and proper utilization of forest. However, very little works have been carried out in Nepal despite contribution of international experts in forest sector. The spiritual valuation of forest ultimately supports forest managers in decision making regarding the management of forest.

\section{Methods ANd Materials}

\subsection{Study Area}

The popular spiritual site called Tapoban (International Commune and Forest Retreat Centre) located at Nagarjun Hills; forest located near Kathmandu in Central Region of Nepal was the study site for this research. The latitude is $29^{\circ} 45^{\prime} 21.2^{\prime \prime}$ North and the longitude is $80^{\circ} 46^{\prime} 50.5^{\prime \prime}$ East (Fig. 1). Average altitude is $1589 \mathrm{~m}$ above mean sea level with more than 90 percent forest cover. Established in 2046 B.S. Tapoban is one of the Nepal's most significant spiritual place which have been a temporal host for numerous visitors coming not only from country but also from all over the world. This area's importance is mainly because of its special natural forest beauty and spiritual life within. This forest receives its name from follower of Buddha named Nagarjuna who was enlightened after meditation in this forest. This forest has immense spiritual value that can be felt by deep silence inside Tapoban. Forest of Tapoban is mix-forest of broad leaved and pine forest with key species such as: Schima wallichi, Castonopsis indica, Pinus wallichiana etc. Forests have always been considered as a spiritual site for the people who aim to use the natural features of such venues in the best way.

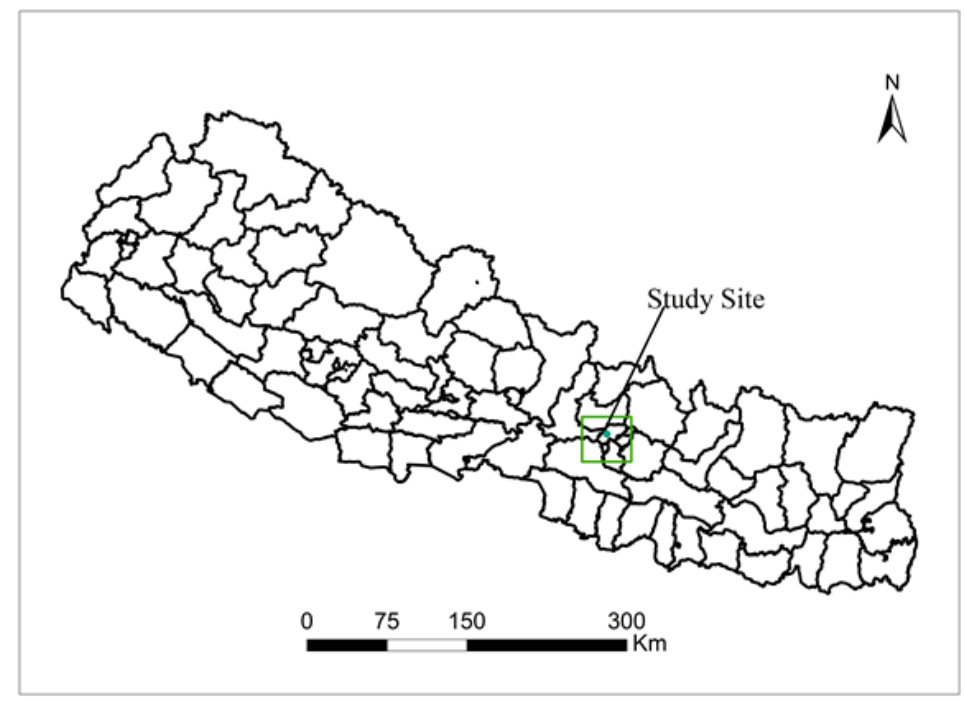

Figure1. Location of Study Area 


\subsection{Data Collection}

This study adopts mainly the primary source for data through face to face interviews using a questionnaire among 45 randomly selected respondents (visitors) within the study site. Focus group discussion was done with the executive members of management committee of Tapoban. The questionnaire includes socio-demographic characteristics like name of respondent, age, nationality, gender, education, income etc costs involved such as number of days and per day expenditure on site. This study analyzes socio-economic characteristics, investment for travelling to the site, travel time, entry fees, activity time, activity costs and food and accommodation costs from the data collected among respondents. Visitors were asked their willingness to pay for the spiritual site. Their perception towards the value of trees and forest inside the Tapoban was also noted. The Likert scale was used to explore the perception of visitors towards the spiritual site. The questions used were multiple choices, dichotomous yes or no; open ended and Likert Scale (five points).

\subsection{Data Analysis}

Travel cost method is widely accepted indirect valuation of forest. This tool estimates visitors benefits of a spiritual site based upon observed travel expenses by visitors to the site (Bertram and Larondelle, 2017). This study adopted travel cost method to determine the proper value of spiritual site. The travel time; the travel cost; activity time; activity cost; including entry fee; lodging and food expenses and other expenses were considered between the starting point of the respondent and Tapoban. Since the benefit accumulated from total expenses and time spend for both traveling and performed activity at site, time value with reference to income of the visitor was calculated for finding spiritual value of site. Thus, the study incurred travel costs for actual trip to site and actual cost incur on actual activity carry inside the spiritual site. Assumption includes the value of on-site time that has similar concept to well-known value of time. Valuation of spiritual site based on travel for the site is determined by using following equation.

$S V=\lambda T T+T C+\lambda \mathrm{AT}+\mathrm{AC}$

$S V=$ Spiritual Value of the site. (Rs)

$\lambda T T=$ Travel time value $(\mathrm{Rs})$

$T C=$ Travel cost value $(\mathrm{Rs})$

Value of time in this study used $\lambda$ to be a representative of unit time value that was used for both travel time and activity time valuation as opportunity cost of the respondents. Separation of benefit from travel time and travel cost is demonstrated in equation (2) and equation (3).

$T T=\lambda T T$

Where:

$\lambda=$ Value of time (Rs/hour)

$T T=$ Travel time to site (hr)

Let total spending for travel is denoted by $T S$ :

$T S=T C+\lambda . T T$

Total spending on the activity in the site is also denoted by

$A S=A C+\lambda \cdot A T$

Where,

$A C=$ Activity expenditure on site $(\mathrm{Rs})$

$A T=$ Activity time perform at site $(\mathrm{Rs})$

By substituting all derivation to equation (1), monetary term of spiritual benefit from

Travel to site in general term was obtained. Time value was calculated by using following equation:

$\lambda=$ Average income of the respondent/Average working hour of the respondent 


\section{RESULTS AND DISCUSSION}

By integrating the methodology of travel cost method together with activity concerned for estimate non-market benefit for spiritual site a case study with several useful result was obtained for forest retreat center; Tapoban. Travel cost method gave simplified and derivation results that are easy to interpret. Actual behavior of the visitors and the activity on site was also included for the effective valuation of the site. The purchasing goods and service for making trips to sites were considered as one innovative approach to estimate this benefit. Total spending was calculated to estimate the nonmarket benefits of site, and it also provides useful idea on the travel and activity concerns. Users who travel longer to park would have tendency to stay longer as well. By using this rational result, this study also calibrated the model to determine the travel and activity factor to site.

Table1.Visitor characteristics

\begin{tabular}{|l|r|}
\hline Variables & Mean (N=45) \\
\hline Age (Yr) & 28.75 \\
\hline Income (NRs/month) & 87377.27 \\
\hline Travel Characteristics & 4.68 \\
\hline Travel time (hr) & 14565.59 \\
\hline Travel cost (NRs) & 78.29 \\
\hline Activity time (hr) & 2812.66 \\
\hline Activity cost (NRs) & 11 \\
\hline No. of visit (nth time) & 4 \\
\hline Working Hours (hr/day) & \\
\hline
\end{tabular}

\subsection{Demand Trend of the Spiritual Site}

The number of visitors in 2046 were 4800, in 2047 were 5000, in 2058 the number slightly increased to 8000 . The number of visitors rapidly increased to 13000 in year 2063 and reached 20000 in 2069 per year till this study year. As the general economic law, the willingness to pay as entry fee for spiritual site is low at higher entry fees and vice versa. 5 respondents of 45 were willing to pay more than Rs. 150. 15 respondents were willing to pay Rs. 100 as entry fee. The figure shows that 20 were willing to pay Rs. 80 and 42 respondents were willing to pay Rs. 60 . The number was 44 , willing to pay NRs. 35. The figure shows the visitors willingness to pay for the site only as entry fee excluding other willingness to pay for different activities.

Value of the spiritual site was determined by using the TCM. Average or per hour value of time was calculated as opportunity cost of the visitor which was NRs. 728.15. All the expenses made by the visitor to visit the spiritual site were included and hence the spiritual valuation of the site was calculated. By substituting all the values in equation (1) the spiritual value of Tapoban was determined. Economic value of spiritual site was Rs. 34512.44 per hour while the mean spiritual value per hour of Tapoban was Rs 784.3737 per hour. The annual economic value of Tapoban is NRs. 6942000 .

\subsection{Role of Forest in Meditation}

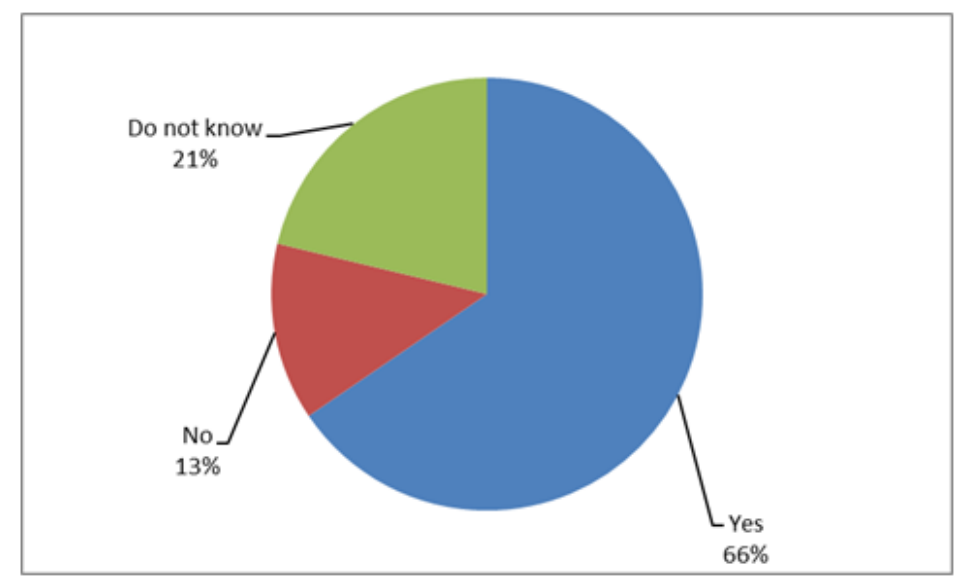

Figure2. Response on role of forest in meditation 
Most of the respondents (66\%) believe that trees and forest have important role in meditation (Figure 2). Among the respondents $21 \%$ said that they don't have idea about the relation of forest and meditation while other $13 \%$ said that there is no relationship between forest and meditation.

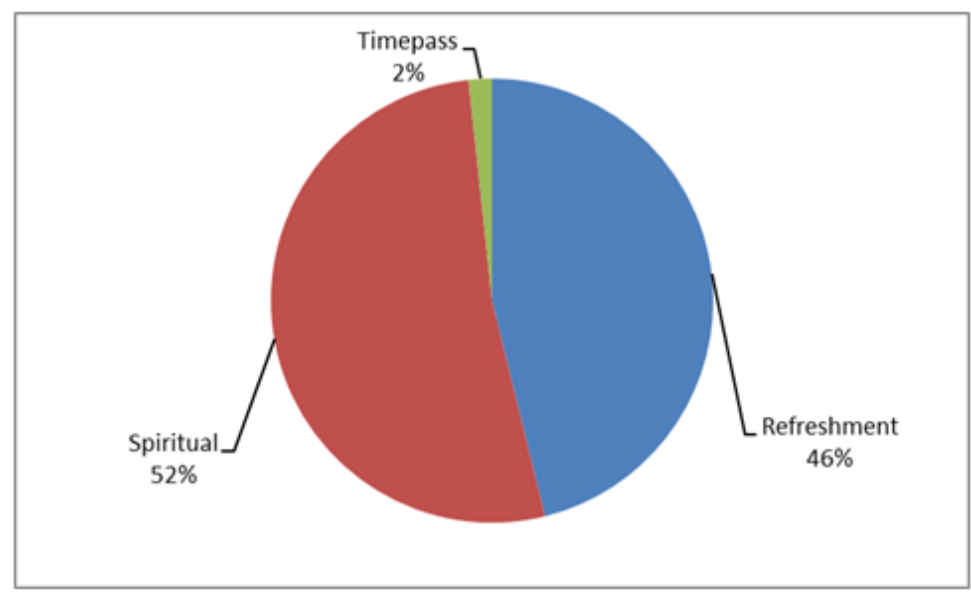

Figure3. Reason for visiting site

People visited Tapoban for different purpose. More than half of the visitors (52\%) came for spiritual purpose while less than half (47\%) visitors came for refreshment. Only $2 \%$ visitors used this forest for leisure (Figure 3).

Nature-based recreation and tourism is touted as a sustainable means to preserve natural resources while providing a diversity of economic benefits to local communities and national economies (Gossling 1999, Wunder 2000). Usually, many factors affect the economic issues, each having a special degree of importance. Other affecting conditions should be typically considered constant when investigating a specific variable's effects. In the curve related to a spiritual site's demand, so many visitors' reactions would be thus ignored to specify the relation between the cost and the amount of uses. Cost dose not solely specify the user's behavior, but it is surely the most effective factor. Twerefou and Ababio (2012) observed a direct relation between the cost and the number of visitors. The relation also holds true for spiritual site, Tapoban. Results of this study showed that improving the environmental condition and/or ecotourism services can have a valuable effect to improve visitor's demands. WTP in such a forest areas for spiritual purpose though other effective factors like costs, users characteristics, distance to site, time needed to reach the site, people's leisure time, amount of working hours, the visitor's job, population residing in the spiritual site, available installations and facilities, and the landscape features actually act a role in the demand. Nevertheless, the improvement of ecological resources/services can be the most significant factor which could be effective in visiting the spiritual site, in addition to the costs and user's income. Accessibility of enough public transportation facilities and good accommodation and food services inside or near the site can persuade many more visitors to visit the area.

\section{CONCLUSION}

Based on the integration of travel cost method and total activity spending, an indirect value of estimation of spiritual site users' benefits has been estimated through an evaluation of expenses on individual approach. Subsequently, the spiritual value was determined from actual cost-behavior of visitors. The assignment of monetary value also demonstrates an intuitive appreciation for environmental valuation based on visitors' expenses made by visitors for spiritual site. It corresponds to the integration of travel expenditure incurred in getting to the site. Total spiritual value of the site was found to be around NRs. 6942000 (US\$ 89000) per year. Hence it is concluded that people have very high willingness to pay for spiritual well-being. Higher economic benefits can be gained from forest management if it considers spiritual use. This study delivers useful message about significant role of forest in generating valuable economic information for local government policymakers, forest managers to place suitable and sustainable forest management for social welfare. It also supports to prepare the best forest management plans maintaining quality of both forest and public to achieve the goal of human wellbeing. Nepalese unique forest should be managed in such a way that it can fulfill the spiritual requirement of the people in the local, national and global scale. 


\section{REFERENCES}

[1] Bertram, C. and Larondelle, N., 2017. Going to the Woods Is Going Home: Recreational Benefits of a Larger Urban Forest Site-A Travel Cost Analysis for Berlin, Germany. Ecological Economics, 132: 255263.

[2] Boyle, K. J. and Richard C. B. 1988. Welfare Measurements Using Contingent Valuation: A Comparison of Techniques. American Journal of Agricultural Economics, 70(1):20-28.

[3] Cooper, N.S., 2019. Examining Evidence of How a Culture Values Nature, Particularly Its Spiritual Value. In Sustainability and the Humanities (pp. 239-266). Springer, Cham.

[4] Costanza, R., d'Arge, R., De Groot, R., Farber, S., Grasso, M., Hannon, B., Limburg, K., Naeem, S., O'neill, R.V., Paruelo, J. and Raskin, R.G., 1997. The value of the world's ecosystem services and natural capital. Nature, 387: 253-260.

[5] Gössling, S., 1999. Ecotourism: a means to safeguard biodiversity and ecosystem functions? Ecological economics, 29(2): 303-320.

[6] De Groot, R.S., Wilson, M.A. and Boumans, R.M., 2002. A typology for the classification, description and valuation of ecosystem functions, goods and services. Ecological economics, 41(3), pp.393-408.

[7] Himes-Cornell, A., Pendleton, L. and Atiyah, P., 2018. Valuing ecosystem services from blue forests: A systematic review of the valuation of salt marshes, sea grass beds and mangrove forests. Ecosystem Services, 30: 36-48.

[8] Hotelling, H. 1947. The economics of exhaustible resources. Journal of Political Economy 39:137-175.

[9] Joshi, A.K. and Joshi, P.K., 2018. Forest Ecosystem Services in the Central Himalaya: Local Benefits and Global Relevance. Proceedings of the National Academy of Sciences, India Section B: Biological Sciences, pp.1-8.

[10] Loomis, J. 1998. Comparing the economic value of mountain biking estimated using revealed. Journal of Environmental Planning and Management 41 (2): 227-236.

[11] Twerefou, D.K. and Ababio, D.K.A., 2012. An economic valuation of the Kakum National Park: An individual travel cost approach. African Journal of Environmental Science and Technology, 6(4): 199-207.

[12] Wunder, S., 2000. Ecotourism and economic incentives - an empirical approach. Ecological economics, 32(3): 465-479.

Citation: Amrit Sharma et al,, "Economic Valuation of Spiritual Site: Case from Tapoban, Nepal", International Journal of Research in Environmental Science (IJRES), vol. 5, no. 1, pp. 11-16, 2019. Available: DOI: http://dx.doi.org/10.20431/2454-9444.0501003.

Copyright: () 2019 Authors. This is an open-access article distributed under the terms of the Creative Commons Attribution License, which permits unrestricted use, distribution, and reproduction in any medium, provided the original author and source are credited. 